\title{
Reshaping Tribal Road Network Using Public Information
}

\author{
Jaesung Choi ${ }^{1}$, EunSu Lee ${ }^{2 *}$, David C. Roberts ${ }^{3}$ \\ ${ }^{1}$ Transportation and Logistics Program, North Dakota State University, Fargo, USA \\ ${ }^{2}$ Upper Great Plains Transportation Institute, North Dakota State University, Fargo, USA \\ ${ }^{3}$ Department of Agribusiness \& Applied Economics, North Dakota State University, Fargo, USA \\ Email: jaesung.choi@ndsu.edu, ${ }^{*}$ eunsu.lee@ndsu.edu, David.C.Roberts@ndsu.edu
}

Received 19 September 2014; revised 16 October 2014; accepted 11 November 2014

Copyright (C) 2014 by authors and Scientific Research Publishing Inc.

This work is licensed under the Creative Commons Attribution International License (CC BY).

http://creativecommons.org/licenses/by/4.0/

(c) (i) Open Access

\section{Abstract}

The area with the fastest growing Native American population in North Dakota is the Fort Berthold Reservation. State and federal road information available to the public is not identical in terms of the number of physical road segments or in the attribute information provided for the road network. In this study we develop: 1) a navigable road network achieved by improving connectivity among road segments, updating road information, and making a comprehensive network; and 2) a standard process for integrating the state and federal local road information. The standard process broadly consists of three Parts: 1) combining road segments from each source; 2) providing legitimacy to snapping distance; and 3) performing a snapping based on the result of Part 2 to connect those road segments, which remained unconnected from Part 1. The findings show that data on local roads on the Fort Berthold Reservation from the two different sources are joined through the standard process, and the process saves considerable time and resources required for fixing the road network. The standard process that has been developed here can be applied to a variety of other Indian road information integration projects to join not only physical road segments, but also plural attribute information. The process will also be useful for a variety of other projects integrating road information, which is available to the public, in order to overcome financial and time limitations.

\section{Keywords}

GIS, Standard Process, Tribal Roads, Geoprocessing, Topology Error, Error Inspection

"Corresponding author. 


\section{Introduction}

As of 2013, 2.9 million residents in the United States are identified as Native Americans and Alaska Natives, and the population growth rate of them is much faster than that of the total US population. From 2000 to 2010 , the Native American and Alaska Native population in the United States has increased by 18.4 percent, while the growth of the total US population was 9.7\%. During that same time, the Native Americans and Alaska Native population in North Dakota grew 16.8 percent [1].

North Dakota Native American reservations include five tribes: Three Affiliated Tribes (Mandan, Hidatsa, and Arikara), Spirit Lake Tribe, Standing Rock Sioux Tribe, Turtle Mountain Band of Chippewa, and SissetonWahpeton Oyate [2]. According to United Census Bureau [3], the Fort Berthold Reservation with Three Affiliated Tribes is where the fastest growth of Indian population in North Dakota occurred from 2000 to 2012, increasing from 3799 to 4275 by $11.1 \%$.

The Fort Berthold Reservation is situated on the Missouri River and includes parts of six counties, McLean, Mountrail, Dunn, McKenzie, Mercer and Ward as shown in Figure 1. The completion of the Garrison Dam construction and the resulting creation of Lake Sakakawea in 1953 caused the Three Affiliated Tribes to move into the uplands or move off the reservation, significantly impacting the lifestyles of the farmers and hunters on the reservation. In 1988, the Indian Gaming Regulatory Act was passed by the US Congress to support the economic stability of the Indian tribes. As a result, the Four Bears Casino and Lodge on the Fort Berthold Reservation was constructed in 1993 and 90\% of the employment was tribal Indians. Currently, recreational and historical facilities are organized to preserve the Three Affiliated Tribes' culture, and there are a few manufacturing firms which provide members of the Three Affiliated Tribes with job opportunities [4] [5].

Commercial deregulation on Indian reservations, an increase in federal and state funding, and the recent oil boom in the Bakken oil field have had an important positive impact on sustainable social and economic development on the Fort Berthold Reservation. Sustainable development requires well-established basic road information, which provides the basis to make improvements in ambulance services, emergency dispatch service, land use management as well as transportation planning [6].

Tribal roads are the primary transportation infrastructure connecting local non-tribal residents and Indian residents for residential, commercial, and social purposes [7]. In 2003, Leichenko [8]] concluded that transportation information plays a significant role in explaining income change across American Indian tribal areas. However, in the Fort Berthold Reservation, current road information is not consistent for state local roads between the North Dakota GIS Hub (ND GIS Hub) and federal local roads from the Topologically Integrated Geographic Encoding and Referencing (TIGER ${ }^{\circledR}$ ) products provided by US Census Bureau. These two official websites

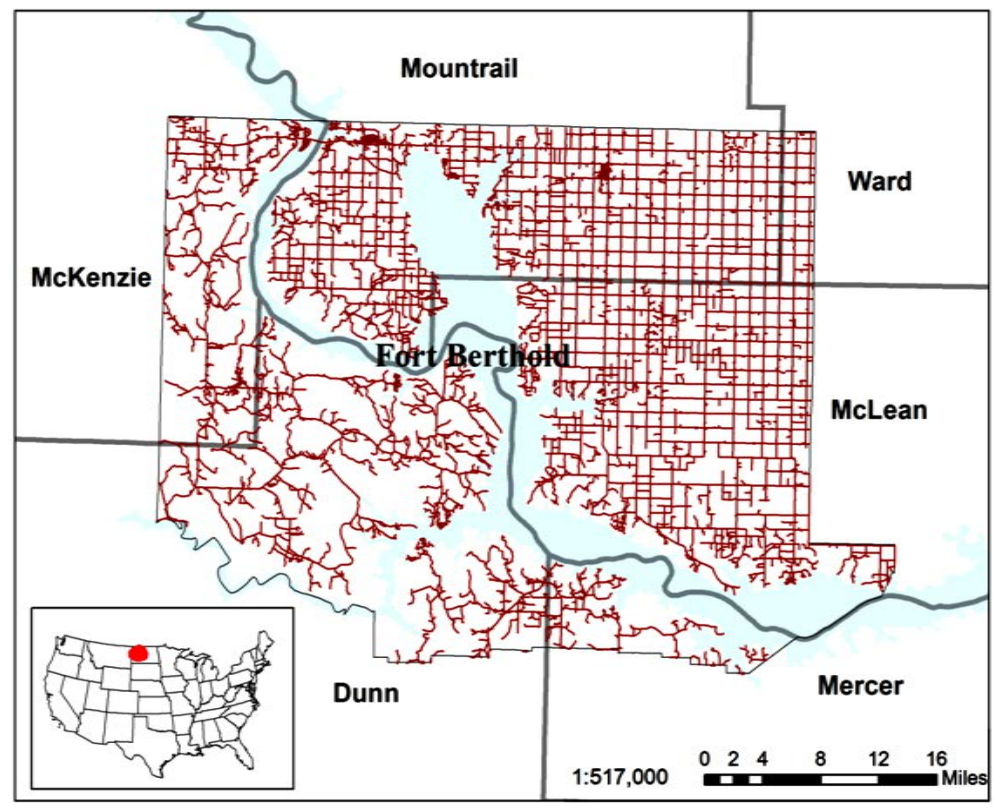

Figure 1. Geographic location and roads of Fort Berthold Reservation. 
are public sources for road information on the Fort Berthold Reservation, but each has similar, but not completely identical road information. Physical road segments in the ND GIS Hub are fewer compared to the US Census Bureau TIGER ${ }^{\circledR}$ as shown in Figure 2 and Figure 3. Note that ND GIS Hub shows more road attribute information. For example, ND GIS Hub provides a variety of road attributes: route functional class, surface type, street name, surface direction, road length, etc., while TIGER ${ }^{\circledR}$ has some information about street name and route type. Figure 2 and Figure 3 below depict each of local loads coming from the two different sources. As shown in the Figure 2 and Figure 3, local roads information from the US Census Bureau TIGER ${ }^{\circledR}$ has more road segments than the information from the ND GIS Hub.

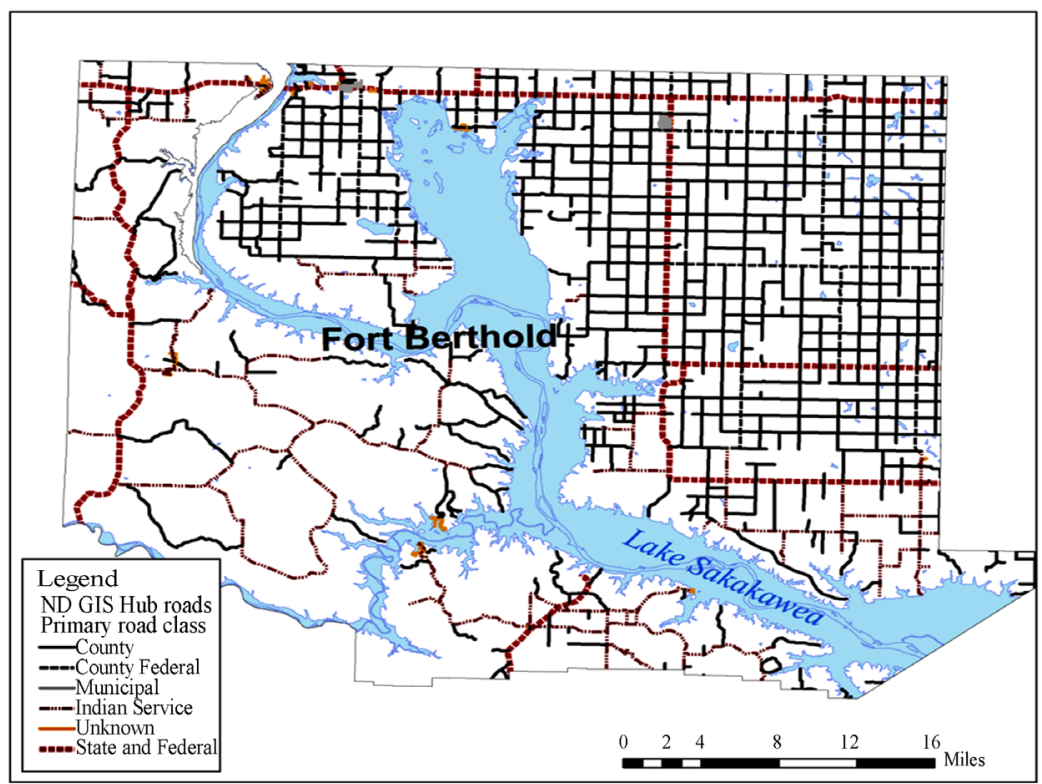

Figure 2. Local roads from ND GIS Hub.

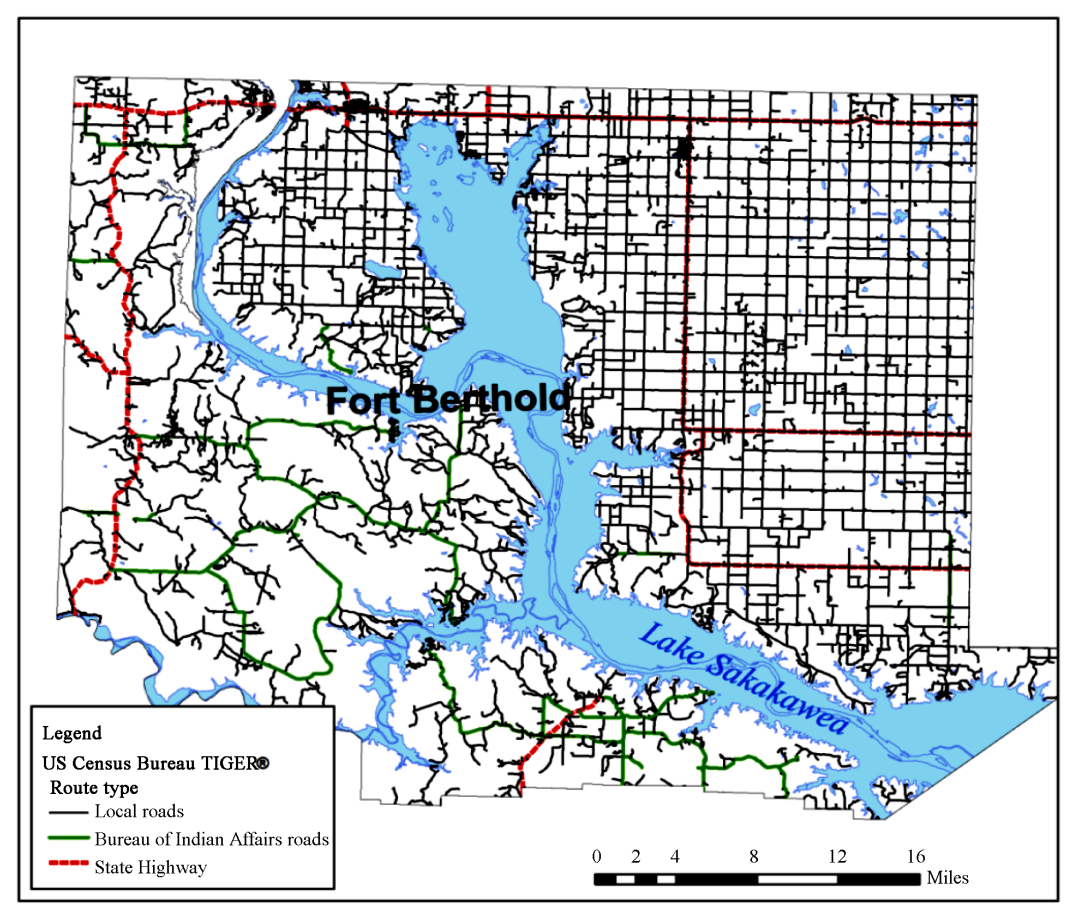

Figure 3. Local roads from the US Census Bureau TIGER ${ }^{\circledR}$. 
The objectives of this paper are to develop 1) a navigable road network on the Fort Berthold Reservation by improving connectivity among road segments, updating road information, and developing a comprehensive network; and 2) a standard process to integrate the state and federal local road information. The remainder of this study is organized as follows: Section 2 discusses methodology to make a standardized integration process, and Section 3 includes a discussion of attribute tables and its construction. Sections 4 and 5 present and discuss the results and conclusions.

\section{Methodology}

Geographic Information Systems (GIS) provides a useful tool for geographic visualization and analysis of the road network [8]. Traditional methods of road design and data management have been changing because of the progress that has been made in applying GIS techniques to road transportation management and the increasing access to user-friendly GIS software by transportation planners [9]. In a report on the Bakken oil field development's impact on Montana State Highways, Dybing et al. [10] developed a geospatial production database of road transportation affected by the oil boom in North Dakota. They located inputs to oil production and their product movements to develop a routable GIS model after applying individual geographic shape files to maps, which do not have overlapped segments and attribute information.

However, integrating road information for the Fort Berthold Reservation is a more complicated situation. The local road information from the two official sources should have the same geographic locations and attributes, but are not identical. Consequently, the process of integrating data from the two sources manually takes a long time: TIGER ${ }^{\circledR}$ has 11,296 road segments on the Indian Reservation and ND GIS Hub has 1607, and the time required to edit and append one integrated road line is approximately 30 minutes. The total number of road lines that need processing is 9689 road segments $(=11,296-1607$ road segments) because we have to cut a road line from TIGER ${ }^{\circledR}$ and paste it to ND Hub which has more road attribute information. The time required to manually edit these 9689 road segments is 20 to 21 months (605 8-hour days). This effort is limited by financial and time constraints. Thus, this paper develops a standard process for integrating two different types of tribal road data sets.

\section{Three Steps for the Standard Process}

The standard process for the integration of road network developed in this study uses the GIS software ArcMap 10.1 and its geoprocessing tools. The process broadly consists of three Parts: 1) combining road segments from each source; 2) providing legitimacy to snapping distance; and 3) performing a snapping based on the result of Part 2 to connect those road segments which remained unconnected from Part 1.

In Part 1, as illustrated in Figure 4, we establish an ideal buffer of $20 \mathrm{~m}$ in ND Hub through a repetitive experiment using various buffer sizes, e.g., $10 \mathrm{~m}, 20 \mathrm{~m}, 30 \mathrm{~m}$, and etc. for selecting the overlapped roads in TIGER ${ }^{\circledR}$. Following a Select Location and a Definition Query, road segments from the overlapped TIGER ${ }^{\circledR}$ road segments are selected: 1) we select a target layer of TIGER ${ }^{\circledR}$ road based on a source layer equivalent to a 20 meter buffer in ND Hub road; 2) a new field column named "Selected" in the attribute table of TIGER ${ }^{\circledR}$ roads is made and overlapped segments are marked as "Overlapped"; and 3) non-overlapped segments are selected through the Definition Query: "Selected" is not equal to "Overlapped".

In Part 2, as illustrated in Figure 5, ND Hub road segments and TIGER ${ }^{\circledR}$ road segments from the buffer area are appended. This resulting road layer shows a "non-planar" characteristic, which means at some locations a line passes over or under another line segment. To solve this, it is necessary to make nodes at each line crossing by: 1) intersecting the appended roads layer from the two inputs to make intersections of road points; and 2) splitting the appended roads layer at the intersected road points through a Split Line at Point. Using the new nodes, the split roads layer performs a Feature Vertices to Points to make dangled road points which are any beginning or ending points of the split roads segments. We test a hypothesis to provide legitimacy to the snapping distance of unconnected road segments left after Part 1. This is performed through a Spatial Join (target feature: dangling nodes, join feature: split roads layer):

$H_{0}$ : A dangling node is connected with a road line of the split roads layer through the spatial join.

$H_{1}$ : A dangling node is connected with two or more road segments of the split roads layer through the spatial join.

If $H_{0}$ is not rejected, then a dangled point is a start point or an end point. Otherwise, a dangled point has the 


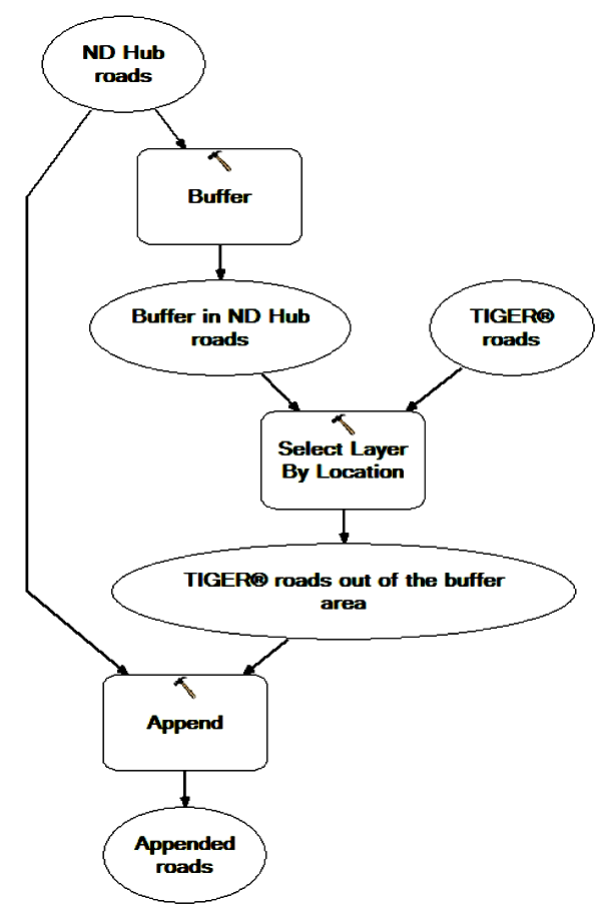

Figure 4. Part 1 of the standard process.

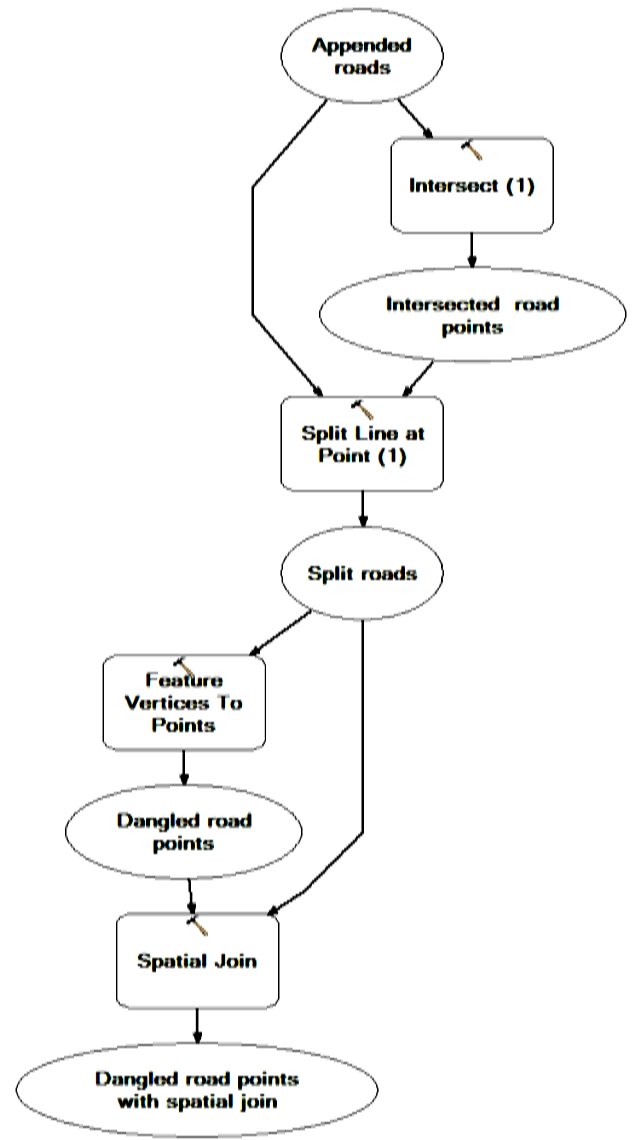

Figure 5. Part 2 of the standard process. 
number of unconnected road segments that should be connected with it. This process measures how far the snapping distance from dangled points is ideal. Experiment with various snapping distances ranging from $1 \mathrm{~m}$ to $17 \mathrm{~m}$ to find the snapping distance that is as accurate as possible is performed. The result of each distance is later explained in the result section. A dangled point does not contain an intersection point of two or more lines, in other words, a 2-way intersection, a 3-way intersection, and so on.

In Part 3 as illustrated in Figure 6, the snapping function is used to connect with road segments after Parts 1 and 2. Snapped road segments are split at the intersected points in the snapped roads through an Intersect. The integrated roads between ND Hub and TIGER ${ }^{\circledR}$ are finally completed.

\section{Attribute Tables}

Before you begin to format your paper, first write and save the content as a separate text file. Keep your text and graphic files separate until after the text has been formatted and styled. Do not use hard tabs, and limit use of hard returns to only one return at the end of a paragraph. Do not add any kind of pagination anywhere in the paper. Do not number text heads - the template will do that for you.

Finally, complete content and organizational editing before formatting. Please take note of the following items when proofreading spelling and grammar: Local roads data are from the ND GIS Hub data portal and US Census Bureau TIGER products, and are available to the public free of charge [11] [12]. Local roads data from US Census Bureau TIGER products has the attribute information of street name and route type code which is classified by county, interstate, state recognized, US, common name, and other. Additional attribute information from the ND GIS Hub data portal includes route functional class, surface type, route ID, route sign, street address, surface direction, and length. Route function class is sorted into local, major collector, and state highway. Surface type includes graded \& drained, gravel, paved, trail, and unimproved. Route ID is classified as 70th, 88th, etc. Route sign classifications include private, Indian service, forest service, federal, local, and municipal. Table 1 shows differences between these two data sources. On the Fort Berthold Reservation, the ND GIS Hub has more attribute information for local roads, but fewer road segments than US Census Bureau TIGER ${ }^{\circledR}$

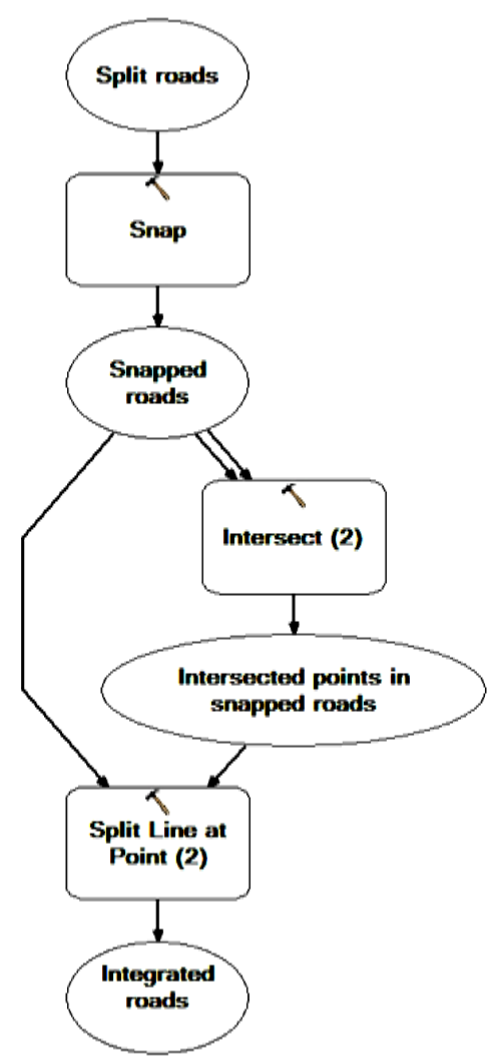

Figure 6. Part 3 in the standard process. 
Table 1. Local roads data of Fort Berthold Reservation in ND Hub and TIGER ${ }^{\circledR}$.

\begin{tabular}{ccc}
\hline Information Available & ND GIS Hub & US Census Bureau TIGER \\
\hline Route Type & X & O \\
Street Type & O & O \\
Route Function Class & O & X \\
Surface Type & O & O \\
Route ID & O & X \\
Route Sign & O & X \\
Lane Direction & O & X \\
Surface Direction & O & O \\
Length & O & 11,296 \\
Number of Road Segments & 1607 & 0.237 miles \\
Average Road Segment Length & 0.818 miles & 2688 miles \\
Total Road Segment Length & 1315 miles & \\
\hline
\end{tabular}

data. The average road segment length in TIGER ${ }^{\circledR}$ is much shorter than ND GIS Hub’s, reflecting better connectivity.

\section{Validation}

For quality assurance purposes, random dummy origin and destination points near and inside the Fort Berthold Reservation were generated: 21 origins are out of the Fort Berthold Reservation; 21 destinations are from within the Fort Berthold Reservation; and 9 origins and destinations are from within the Fort Berthold. In Figure 7, we confirm the good connectivity where each origin point was connected to the closest destination point.

\section{Results}

Data on local roads on the Fort Berthold Reservation from the two different sources are joined through the standard process in Figures 4-6. The ideal snapping distance from dangled points is shown in Table 2. In Table 2, the number of unconnected road segments is the largest at the hypothetical snapping distance of 17 meters. As the snapping distance from dangled points increased, the more unconnected road segments exist. The proportion of unconnected road segments to total road segments fast increases at the initial stage from 1 to 4 meters, but after that it slowly increases, and then shows a rate of increase within 1 percent in the distances of 14 to 17 meters. The ideal snapping distance of 15 meters was selected because it has one of the smallest rates of increase.

Given the final snapping distance chosen, the snapping function was performed to connect unconnected road segments. Figure 8 is an example of how unconnected road segments are connected through the snapping that we used. (A1) and (B1) are road segments located on 68th Avenue and 65th Avenue on Fort Berthold Reservation and show unconnected road segments, but the (A2) and (B2) road segments were connected after the snapping.

With the physical integration of the two local roads, their attribute road information is also joined to provide the integrated road information in Table 3 . Table 3 is a product of the attribute table from the ND GIS Hub and attribute table from US Census Bureau TIGER ${ }^{\circledR}$. The data was integrated as much as possible, and the final attribute table in Table 3 has the following attribute information: source, segment ID, state and county FIPS information, full name, route ID, surface direction, street type, lane direction, surface type, route sign, shape 


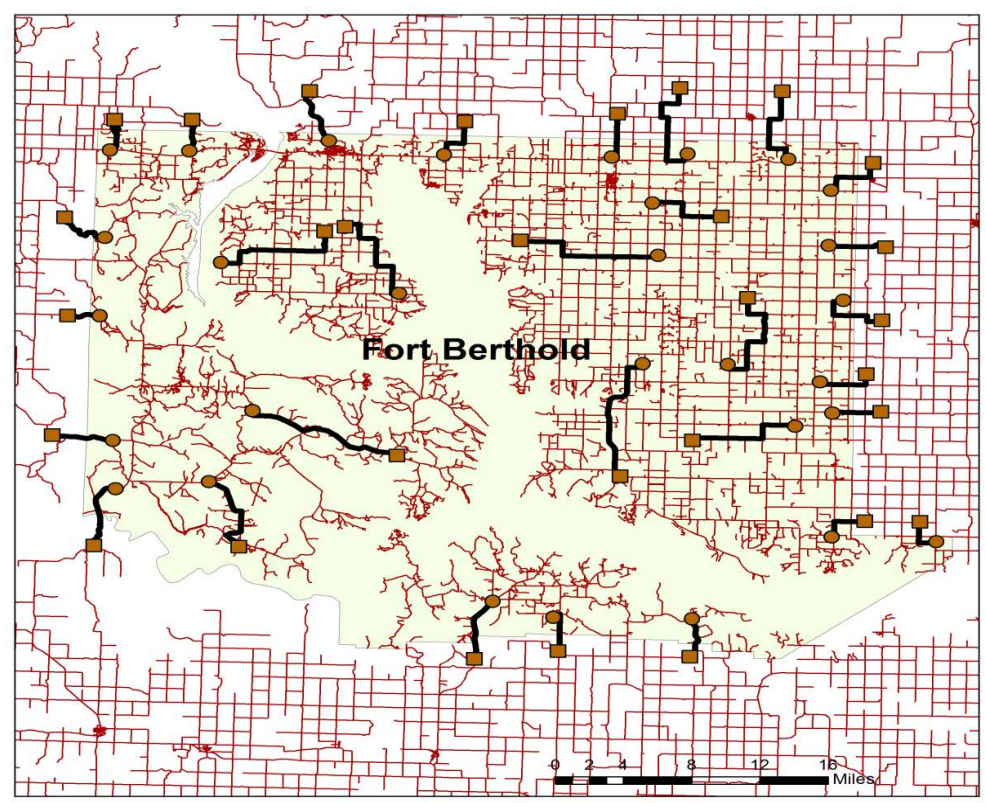

Figure 7. Validity test of the integrated road network (sample).

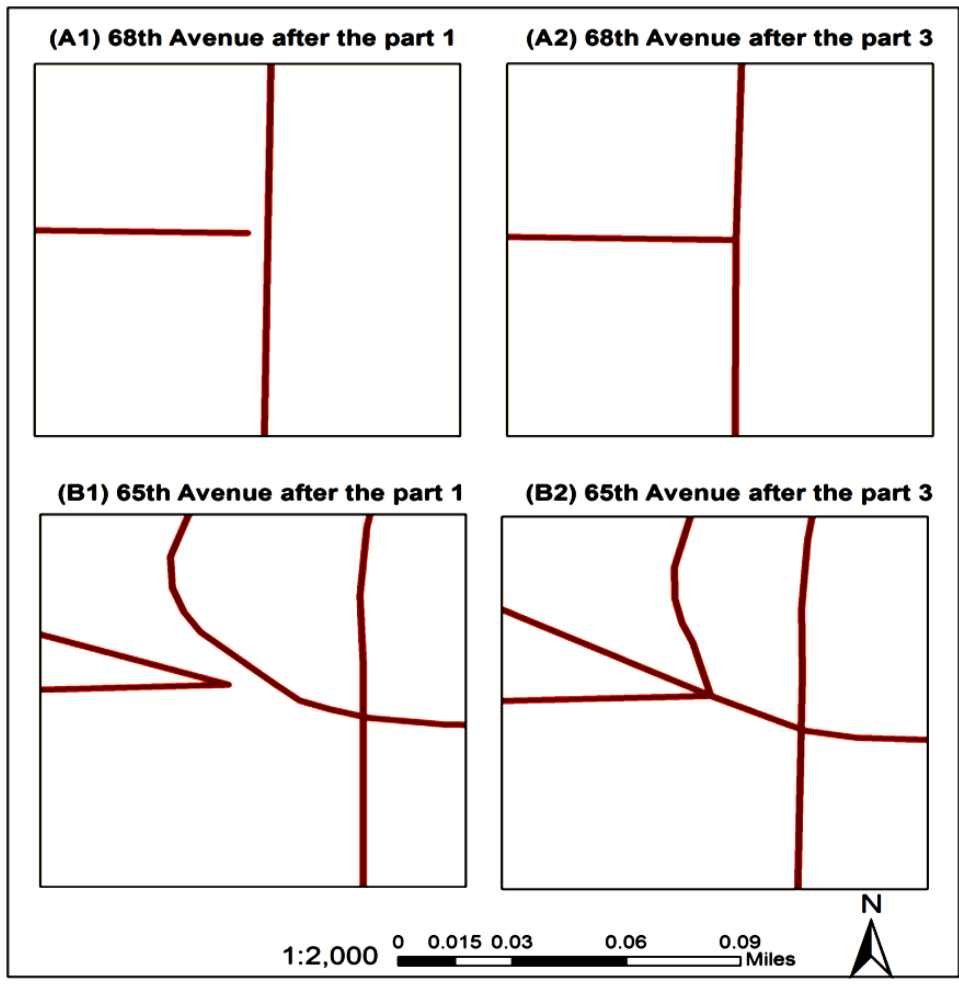

Figure 8. Road segment examples Before (A1 \& B1) and After (A2 \& B2) snapping.

length, speed, and sub-segment ID. Source and segment ID identifies where the road information is from and what each unique ID is respectively before appending the two roads in Part 1. Speed information of road segments is created through the use of the Upper Great Plains Transportation Institute (UGPTI) road network [13], and sub-segment ID is the unique identification for every road segments after final GIS framework is established in Part 3. 
Table 2. Hypothetical snapping distances from danged points and the proportion of unconnected road segments in the total road segments.

\begin{tabular}{|c|c|c|c|c|}
\hline Snapping Distance (m) & Unconnected & Total & Unconnected/Total (\%) & Increasing Rate (\%) \\
\hline 1 & 366 & 3882 & 9.43 & - \\
\hline 2 & 657 & 3882 & 16.92 & 79.51 \\
\hline 3 & 840 & 3882 & 21.64 & 27.85 \\
\hline 4 & 972 & 3882 & 25.04 & 15.71 \\
\hline 5 & 1.067 & 3882 & 27.49 & 9.77 \\
\hline 6 & 1.152 & 3882 & 29.68 & 7.97 \\
\hline 7 & 1.229 & 3882 & 31.66 & 6.68 \\
\hline 8 & 1.271 & 3882 & 32.74 & 3.42 \\
\hline 9 & 1.317 & 3882 & 33.93 & 3.62 \\
\hline 10 & 1.352 & 3882 & 34.83 & 2.66 \\
\hline 11 & 1.377 & 3882 & 35.47 & 1.85 \\
\hline 12 & 1.404 & 3882 & 36.17 & 1.96 \\
\hline 13 & 1.424 & 3882 & 36.68 & 1.42 \\
\hline 14 & 1.435 & 3882 & 36.97 & 0.77 \\
\hline 15 & 1.448 & 3882 & 37.30 & 0.91 \\
\hline 16 & 1.461 & 3882 & 37.64 & 0.90 \\
\hline 17 & 1.473 & 3882 & 37.94 & 0.82 \\
\hline
\end{tabular}

Figure 9 shows the final road map for the Fort Berthold Reservation, and is the result of integrating two sets of local roads data from the ND GIS Hub data portal and US Census Bureau TIGER products through a standard process that was developed. Even though the process has been completed, some road segments still need to be corrected. However, any manual editing is only required to connect the unconnected road segments, resulting in a very small workload. The snapping based on the result in Table 2 connects most of unconnected road segments, but does not guarantee a perfect road integration. A longer snapping distance can be used, but may result in incorrect connections. For instance, if snapping distance continues to increase beyond a particular distance, it could connect segments that are already connected to other roads, which should not be connected.

\section{Conclusion}

A well-organized road network can considerably contribute to the prosperity of society. In North Dakota, the Fort Berthold Reservation has undergone a significant change, driven by a variety of factors such as oil development in the Bakken formation, commercial deregulation on tribal land, and continuous population increase in American Indians. Accurate and consistent road information can be a positive factor for continued cultural, economic, social development. In this paper, we developed a standard process to integrate road information data coming from state and federal sources for the Fort Berthold Reservation, and applied a three-part integration process to producing integrated road information. The process saved considerable time and resources required for fixing the road network. The standard process that has been developed here can be applied to a variety of other Indian road information integration projects to join not only physical road segments, but also plural attribute information. Beyond this category the developed GIS tool also may be used in the process of integrating general road information. 


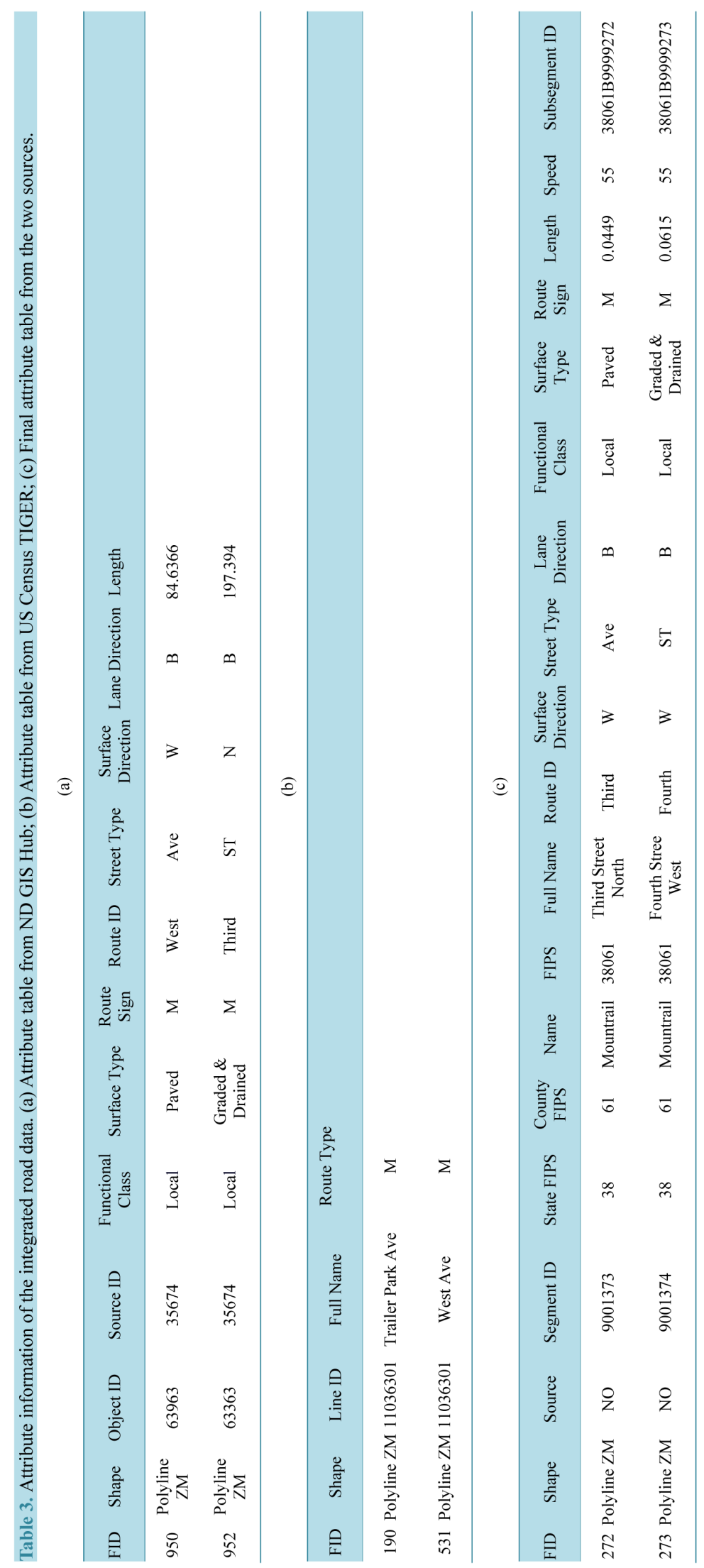




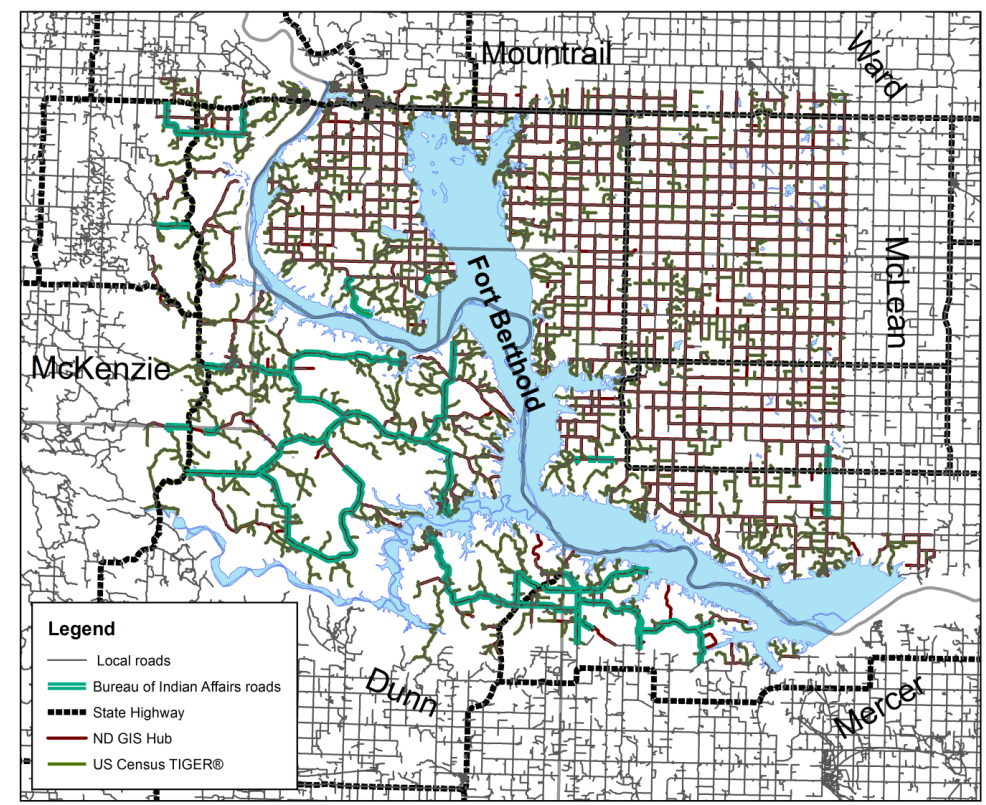

Figure 9. The final road map for Fort Berthold Reservation.

\section{Acknowledgements}

This research was supported by Mountain-Plains Consortium, which is sponsored by the US Department of Transportation through its university Transportation Centers Program. The contents are sole responsibility of the authors. The authors also would like to thank anonymous reviewers for their constructive comments.

\section{References}

[1] US Census Bureau (2014) The American Indian and Alaska Native Population 2010. http://www.census.gov/2010census/data

[2] North Dakota Indian Affairs Commission (2014) Statistics. http://www.nd.gov/indianaffairs/?id=37

[3] US Census Bureau (2014) American Fact Finder. http://factfinder2.census.gov/faces/nav/jsf/pages/searchresults.xhtml?refresh=t\#none

[4] North Dakota State Government (2014) Mandan, Hidatsa, and Sahnish. http://www.ndstudies.org/resources/IndianStudies/threeaffiliated/historical_overview.html

[5] Mandan, Hidatsa, and Arikara Nation (2014) MHA History. http://www.mhanation.com/main2/history.html

[6] Lee, E. (2014) Designing Service Coverage and Measuring Accessibility and Serviceability of Rural and Small Urban Ambulance Systems. Systems, 2, 34-53. http://dx.doi.org/10.3390/systems2010034

[7] Glaze, J. (2012) Current Transportation Issues in Indian County. http://www.gpo.gov/fdsys/pkg/CHRG-110shrg37860/html/CHRG-110shrg37860.htm

[8] Rebolj, D. and Sturm, P. (1999) A GIS Based Component-Oriented Integrated System for Estimation, Visualization and Analysis of Road Traffic Air Pollution. Environmental Modelling \& Software, 14, 531-539. http://dx.doi.org/10.1016/S1364-8152(99)00017-1

[9] Abdi, E., Majnounian, B., DaRvishsefat, A., Mashayekhi, Z. and Sessions, J. (2009) A GIS-MCE Based Model for Forest Road Planning. Journal of Forest Science, 4, 171-176.

[10] Dybing, A., Lee, E.S., DeHaan, C. and Dharmadhikari, N. (2013) Impacts to Montana State Highways Due to Bakken Oil Development. The State of Montana Department of Transportation. http://www.mdt.mt.gov/other/research/external/docs/research proj/oil boom/final report.pdf

[11] Leichenko, R.M. (2003) Does Place Still Matter? Accounting for Income Variation across American Indian Tribal Areas. Economic Geography, 4, 365-386.

[12] North Dakota State Government (2014) GIS Hub Data Portal. https://apps.nd.gov/hubdataportal/srv/en/main.home

[13] Upper Great Plains Transportation Institute (2014) UGPTI Road Network. http://www.ugpti.org/

[14] US Census Bureau (2014) Geography. http://www.census.gov/geo/maps-data/data/tiger.html 
Scientific Research Publishing (SCIRP) is one of the largest Open Access journal publishers. It is currently publishing more than 200 open access, online, peer-reviewed journals covering a wide range of academic disciplines. SCIRP serves the worldwide academic communities and contributes to the progress and application of science with its publication.

Other selected journals from SCIRP are listed as below. Submit your manuscript to us via either submit@scirp.org or Online Submission Portal.
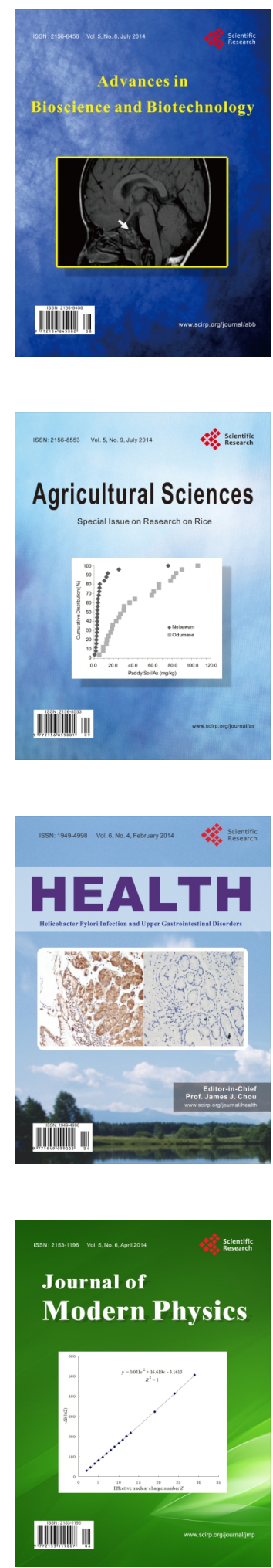
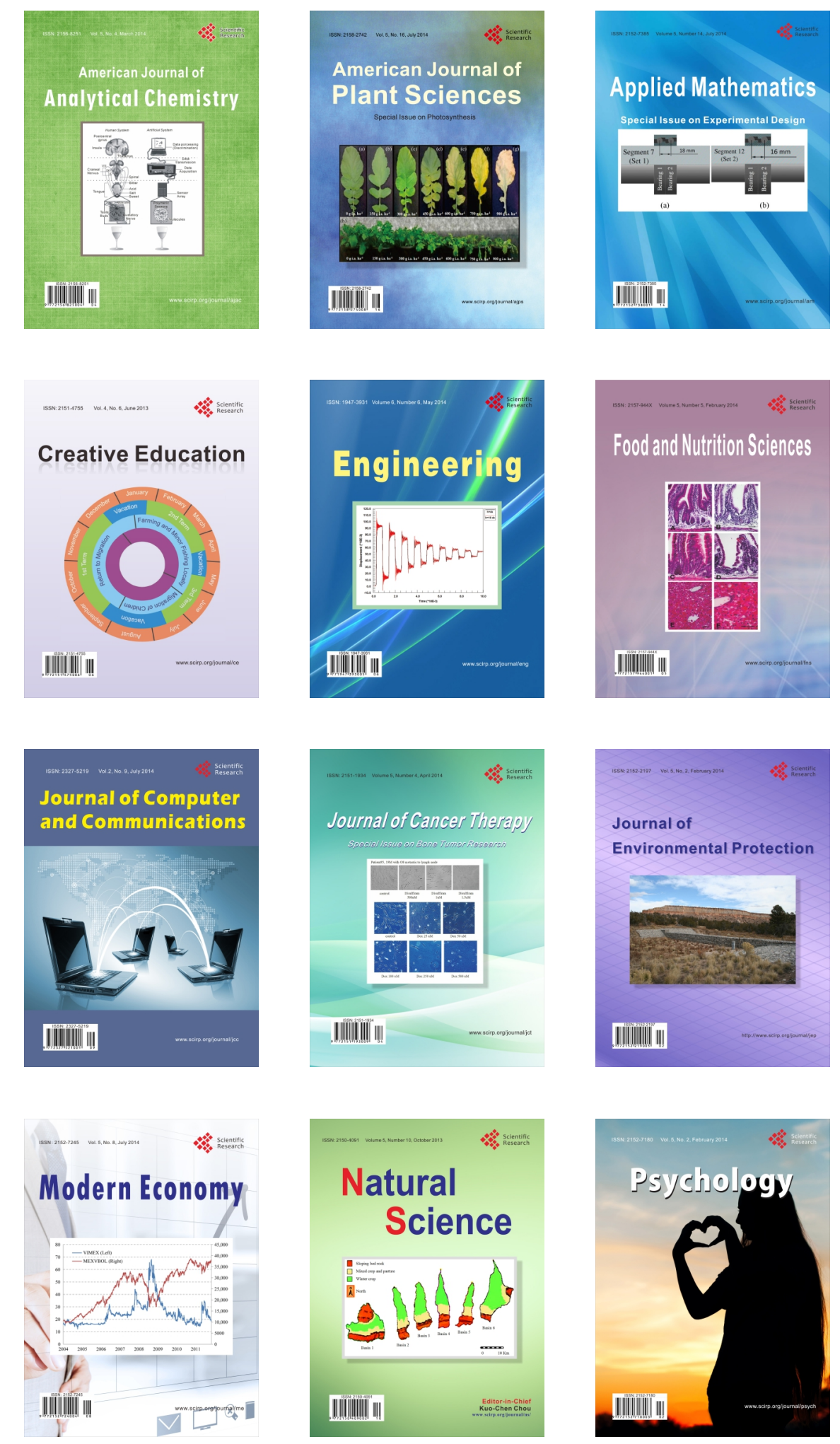